\title{
MODEL FOR SOCIAL MARKETING IMPACT ON CONSUMERS HEALTHY LIFESTYLE CHOICE
}

\author{
Justė STATNICKAITÉ, Monika PAULE் (iD* \\ Department of Management, Faculty of Business Management, Vilnius Gediminas Technical University, \\ Sauletekio av. 11, LT-10223, Vilnius, Lithuania
}

Received 25 February 2021; accepted 1 April 2021

\begin{abstract}
Purpose - the purpose of this article is to present the novel model developed to measure social marketing impact on consumers choice for healthy lifestyle. Social marketing is very complex by aiming to promote socially responsible products and behavior for the benefit of the consumer and society at the same time. What is more, consumers choice for healthy lifestyle is determined not only by marketing influence but other personality and external environment factors as well.

Research methodology - the model presented in the article was developed based on literature analysis and secondary data.

Findings - social marketing impact on consumers choice for healthy lifestyle is determined not only by the social marketing, but also the consumer personality itself and the influence of the external environment on consumer.

Research limitations - validation of the novel developed model dedicated for the measurement of social marketing impact on consumers choice for healthy lifestyle should be further validated with quantitative research methods.

Practical implications - the application of the model will enable marketing specialists to determine the contents and other situational details of social marketing for consumers to choose healthy lifestyle and products related to it.

Originality/Value - the value of the model is determined by its novel attitude to social marketing in parallel with other factors affecting consumer behaviour.
\end{abstract}

Keywords: social marketing, healthy lifestyle, social impact, social responsibility, marketing communications.

JEL Classification: M31, I12.

Conference topic: Contemporary Organizations Development Management.

\section{Introduction}

A healthy lifestyle is a particularly relevant topic these days. We are seeing more and more factors shaping healthy lifestyle habits in social media, outdoor advertising or everyday life, so with this trend gaining popularity, companies should also take this aspect into account and steer their marketing strategy and communication in this direction. As the trend of healthy lifestyles becomes more popular, and the society is seeking for new solutions, thus social marketing is rapidly expanding in the field of public health. About two thirds of the European Union's population spends between 2.5 and 8.5 hours a day sitting, and the majority of those who spend around 5.5 hours a day are young people aged 15-24 (Eurobarometer, 2017). Given the data provided and the fact that we live in a world of online technology, it is not difficult to see that properly used social marketing strategies could help overcome deep-rooted lifestyle issues.

In emphasizing the relevance of the issue, it is important to note that many authors emphasize the importance of social marketing in society and distinguish different approaches to the impact of this discipline in different aspects. The topic of social marketing is analyzed very extensively in the scientific literature, especially in terms of the impact on consumer behavior and the promotion of fair consumer habits. Lee and Kotler (1971) analyzed social marketing as an effort focused on factors shaping consumer behavior that promote healthier lifestyles, Goldberg et al. (2018) viewed social marketing as a change in behavior in general, and French and Gordon (2019) examined social marketing as a set of ethical principles that intertwines with the general principles and tools of marketing theory.

*E-mail: monika.paule@vilniustech.lt

(C) 2021 Authors. Published by Vilnius Gediminas Technical University. This is an open-access article distributed under the terms of the Creative Commons Attribution (http://creativecommons.org/licenses/by/4.0/) License, which permits unrestricted use, distribution, and reproduction in any medium, provided the original author and source are credited. 
In the field of social marketing research, there has recently been a clear focus by researchers on social good, which is defined as a purposeful action done intentionally in the public interest (Shawn, 2015). Slade et al. (2017) emphasized social marketing as a creative, strategic, interdisciplinary, and multifaceted approach to shaping and maintaining social good based on common marketing principles, and Gordon et al. (2016) argued that social marketing is one way to drive social change and promoting social good. Based on the analysis of the scientific literature, it has been observed that social marketing and its impact on consumers' healthy lifestyle choices require more in-depth research. The authors aimed to determine which elements of social marketing most influence consumers in choosing a healthy lifestyle and how consumers value and respond to social marketing. This work will help shape social marketing as an approach that can be effective, targeted and fair in promoting people's well-being, healthier lifestyles and social well-being by providing comprehensive theoretical model for determination of social marketing on consumers in choosing healthy lifestyle in particular.

It is important to know that the impact of marketing on the consumer depends not only on the marketing tools chosen, but also on the environmental factors, personality, and attitudes that also affect the consumer. This means that the social marketing tools used are not universal and work differently depending on the consumers and the factors that affect them. As a result, sometimes some marketing tools are ineffective, and others are more effective and have a targeted impact on consumer attitudes. Against this background, it can be argued that it is still unclear which social marketing tools have the greatest impact on consumers' healthy lifestyle choices. In the scientific literature, social marketing is examined quite extensively in various aspects, but after analyzing the scientific literature in-depth, it can be said that in today's world the problem of not reaching a unanimous conclusion on the impact of social marketing on healthy living still exists.

\section{Theoretical analysis of social marketing impact on consumers}

\section{The concept of social marketing}

Social marketing, as a term and a field of science, is still unfamiliar to most, misunderstood, and often confused with other terms such as social network marketing, social media, or behavioral economics. Given that social marketing as a term is misunderstood, the business sector is still afraid to use it to avoid misunderstandings and misleading associations. So to understand the impact of social marketing on the consumer, it is worth first dispelling doubts and understanding what the social marketing truly is (Lee \& Kotler, 2015) is. The term "social marketing" was coined by Kotler and Zaltman in 1971. Researchers who have studied theories of psychology, sociology, anthropology, political science and communication, as well as advertising, public relations and market research, define social marketing as "the application of commercial sector principles and methods to influence target audiences to accept, modify or reject behavior for the benefit of individuals, groups, organizations or society as a whole, with the aim to create positive social change" (Serrat, 2017, pp. 120-121). According to the authors, social marketing can be used to promote useful products and services or to force the target audience to avoid harmful products and services and thus promote their well-being (Serrat, 2017).

According to Lee and Kotler (2015), social marketing is a clear marketing discipline that has been named so since the early 1970s and primarily refers to efforts focused on shaping consumer behavior that improves health, prevents injuries, protects the environment, contributes to communities and increases financial satisfaction and stability. In 2013, the first general definition of social marketing was developed and approved. The International Social Marketing Association together with the European Social Marketing Association and the Australian Social Marketing Association determined as follows: "Social layout aims to develop and integrate marketing concepts with communities' perspectives for the better" (French \& Gordon, 2019).

Meanwhile, Goldberg et al. (2018) define social marketing as a change in. According to the authors, social marketing is not related to education or propaganda, and individuals accessing social marketing should first understand that the main purpose of social marketing is not to inform the public or to try to change their values. Based on these insights, it becomes clear that social marketing is not only a social advertising or social communications, but much more (Goldberg et al., 2018). Andreasen (1994, p. 110) even equated social marketing with commercial marketing, by stating that "Social marketing is the application of commercial marketing technologies to programs to influence voluntary behavior of target audiences to to improve their personal well-being and that of the society of which they are a part".

The idea of social marketing has existed in society for a long time, but only in recent years scientists have begun to go deeper and discover and present new paradigms, conclusions and approaches. For example, Gordon et al. (2016), based on other authors, defines social marketing as one of the ways in which social change takes place in society and promotes social good. According to the author, the goal of social marketing is to develop and integrate the concept of marketing together with other theories and approaches - to find out how to influence consumer behavior for the benefit of individuals and communities in the name of greater social good. Thus, essentially according to Gordon, social marketing is a paradigm aimed at achieving greater social good and positive change in society (Gordon et al., 2016). 
Slade et al. (2017) also analyzed the concept of social marketing and social good. According to the authors, social marketing in the $21^{\text {st }}$ century is a creative, strategic and interdisciplinary approach to facilitate and maintain social good based on common marketing principles. From the very beginning, social marketing has been applied to various issues related to health and social life of individuals, and the most important link in social marketing is society and each individual. Thus, the main goal of social marketing is to create social good, which brings fairer, cleaner, more productive, and happier life for society and the individual (Slade et al., 2017).

An interesting and exclusive approach to social marketing was outlined by Almestahiri et al. (2017). According to researchers, social marketing is not just advertising and communication, but a strong link between all elements of 4P's marketing complex: social marketing creates attractive benefits for packaging by minimizing the cost, making exchanges easy, whereas the strong communication message on media brings not only commercial but also social benefits to the target audience. The characteristics of social marketing singled out by the authors were determined on the basis of various studies: studies on the effects of healthy eating, alcohol consumption, childhood obesity, and community social marketing.

Social marketing in theory is also defined as an intervention strategy in the areas of healthy lifestyle and health. This view is set out by Firestone et al. (2017) in their research on effectiveness of social marketing in health issues. According to the authors, social marketing uses a general marketing concept - product design, appropriate pricing, sales and distribution channels, and effective communication - to influence consumer behavior that benefits not only individuals but also community. Based on Firestone and others (2017), social marketing typically aims to ensure that the chosen target audience adheres to the behavior being promoted and that health care products or services are attractive to consumers and encourage their willingness to change. Essentially, social marketing sells behaviors: products that encourage certain behaviors (e.g., sporting goods) or services that directly demonstrate the aspirations desired by the target audience. According to the authors, social marketing is most often used as a tool for shaping attitudes towards health care worldwide to reach the most vulnerable target groups through health care products or services. However, according to researchers, social marketing alone is difficult to achieve behavioral change - even if social marketing can encourage people to try products or services, it is still unclear whether such behavior can be sustained in the long run, so researchers conclude that social marketing can only be effective in the case where the attitude of a person or society is influenced not only in a favorable social means, but also other factors as well (Firestone et al., 2017).

Table 1. Social marketing concept (source: developed by authors)

\begin{tabular}{|c|c|c|}
\hline Author & Factor & Definition \\
\hline $\begin{array}{l}\text { Kotler and Zaltman } \\
\text { (1971) }\end{array}$ & \multirow{4}{*}{ 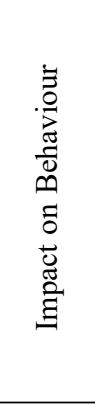 } & $\begin{array}{l}\text { The application of commercial sector principles and methods to influence the target audience } \\
\text { to voluntarily accept, reject, modify, or abandon behavior for the benefit of individuals, } \\
\text { groups, organizations, or society as a whole, aims to create positive social change. }\end{array}$ \\
\hline Andreasen (1994) & & $\begin{array}{l}\text { Social marketing is the application of commercial marketing technologies to programs } \\
\text { designed to influence the voluntary behavior of target audiences to improve the personal } \\
\text { well-being of them and the society of which they are a part. }\end{array}$ \\
\hline Lee and Kotler (2015) & & $\begin{array}{l}\text { A clear marketing discipline }[\ldots] \text { focused on shaping consumer behavior that improves health, } \\
\text { prevents injuries, protects and preserves the environment, contributes to communities, } \\
\text { and increases financial satisfaction and stability. }\end{array}$ \\
\hline Goldberg et al. (2018) & & Social marketing is defined as a change in behavior. \\
\hline $\begin{array}{l}\text { International Social } \\
\text { Marketing Association } \\
\text { (iSMA) (2013) }\end{array}$ & \multirow{4}{*}{ 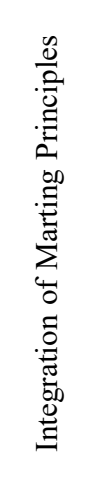 } & $\begin{array}{l}\text { Social layout seeks to develop and integrate the marketing concept along with other } \\
\text { approaches to make a positive impact on consumer behavior and communities for the greater } \\
\text { good. }\end{array}$ \\
\hline $\begin{array}{l}\text { Almestahiri et al. } \\
(2017)\end{array}$ & & $\begin{array}{l}\text { Social marketing is not just advertising and communication, but a strong link between } \\
\text { all elements of 4P's marketing complex: social marketing creates attractive benefits for } \\
\text { packaging by minimizing cost, making exchanges easy, whereas the strong communication } \\
\text { message on media brings not only commercial but also social benefits to the target audience. }\end{array}$ \\
\hline Firestone et al. (2017) & & $\begin{array}{l}\text { Social marketing uses a general marketing concept - product design, appropriate pricing, } \\
\text { sales and distribution channels, and effective communication - to influence consumer } \\
\text { behavior that benefits not only individuals but also community. }\end{array}$ \\
\hline $\begin{array}{l}\text { French and Gordon } \\
\text { (2019) }\end{array}$ & & $\begin{array}{l}\text { Social marketing is guided by ethical principles, seeking to integrate various disciplines } \\
\text { and forms to design social change programs that are effective and sustainable. }\end{array}$ \\
\hline Gordon et al. (2016) & \multirow{2}{*}{ 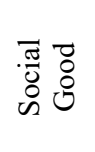 } & $\begin{array}{l}\text { Social marketing is the way how social change takes place in society and promotes social } \\
\text { good. }\end{array}$ \\
\hline Slade et al. (2017) & & $\begin{array}{l}\text { Social marketing is a creative, strategic and interdisciplinary approach to facilitate } \\
\text { and maintainsocial good based on common marketing principles. }\end{array}$ \\
\hline
\end{tabular}




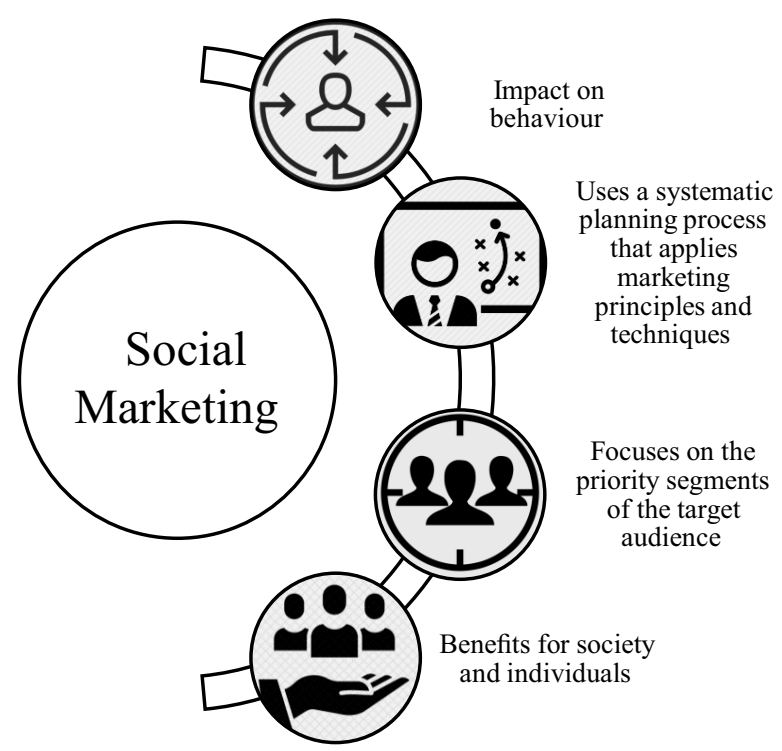

Figure 1. Social Marketing application areas (source: developed by authors based on Lee \& Kotler (2015))

Summarizing the concepts of social marketing presented by the authors (see Table 1), it can be observed that in the definitions of social marketing, the authors clearly emphasize the influence on consumer behavior, integration of marketing principles and dissemination of social good. Researchers, in defining social marketing, agree that social marketing encompasses the following areas of activity: influencing consumer behavior, systematic planning based on marketing principles and methods, focusing on the target segment, and the benefits of social marketing to the individual and society rather than business (see Figure 1).

\section{The concept of a healthy lifestyle}

After analyzing the concept and actions of social marketing, it is worth further discussing the impact of this discipline on consumers' choice of a healthy lifestyle. But before that, it's important to define what a healthy lifestyle means and how it is understood.

According to the World Health Organization, the definition of a healthy lifestyle has not changed for years, so it can be defined as the steps, actions and strategies people use to achieve health and well-being. Healthy life requires a balance between responsible and intelligent health choices, proper nutrition, daily physical activity, emotional and spiritual stability, adequate sleep, giving up harmful substances, avoiding stress, ensuring good work and personal life balance (World Health Organization, 1999).

According to Kottke et al. (2016), a healthy lifestyle plays an important role in maintaining overall health, as it consists of a complete diet (eating natural, nutritious foods, avoiding foods high in fat), physical activity (a daily routine involving various forms of exercise). Promoting a healthy lifestyle can prevent most chronic diseases (cardiovascular, diabetes, depression, cancer), so it is important to adhere to the four principles of a healthy lifestyle: proper nutrition, adequate physical activity, limited tobacco and alcohol use, and excellent psychological status. It is also important to mention that a healthy lifestyle and a predisposition to such a lifestyle depends not only on the factors listed above, but also on beliefs, values, and attitudes (McGovern et al., 2018).

In sociology, lifestyle is also described as human life (Robards, 2014). Our emotions, thoughts, and behaviors play an important role in our health, which affects not only our daily health but also the functioning of the body. According to Robards (2014), today society faces more chronic diseases than ever before because people live longer and often behave not healthy. The progression or occurrence of chronic diseases is primarily determined by the lifestyle, which, according to the author, consists of physical activity, wholesome food, sleep quality, mental health and stress avoidance (Robards, 2014).

Researchers Rauf bin Ridzuan et al. (2018) conducted several studies on healthy lifestyle and its meaning for a person. According to the authors, there have been many campaigns on healthy living in the last years to raise public awareness of living healthier, but despite all efforts to encourage people to adopt a healthy lifestyle, some still do not follow the advice given and continue to live without care. Giving up old eating and social habits is not easy, but it is neither possible nor impossible (Rauf bin Ridzuan et al., 2018). According to the authors, there are many ways to make your life healthier. The first rule is to monitor the food you consume and its amount, exercise enough, and learn 
to manage stress. Robards (2014) argues that one of the most important benefits of a healthy lifestyle is that it can help prevent chronic diseases like cardiovascular disease as well as diabetes or cancer.

Summarizing the concept of a healthy lifestyle, it can be stated that a healthy lifestyle is a complete state of physical, mental, and social well-being, not just the absence of disease or disability (Ioan-Sabin $\&$ Pomohaci, 2018). A healthy lifestyle can be practiced by everyone, regardless of their gender, age and social status, and as a key to a healthy lifestyle, the authors single out three main things: finding a balance between what food and drink, regular exercise, and mental health (see Figure 2).

Proper nutrition. It is the most important principle of a healthy lifestyle. In recent years, the concept of food has changed radically, with food playing an important role in maintaining health, a psychophysical state of well-being, and in preventing certain diseases (Azzurra \& Paola, 2009). According to L. C. De and T. De (2019) a healthy diet depends on the food consumed and the amount of water consumed. A proper diet should include a liberal number of seeds, nuts, grains, vegetables, and fruits that provide enough of all the necessary nutrients (L. C. De \& T. De, 2019).

Physical activity is one of the essential principles of a healthy lifestyle. Individuals engaged in sports activities can improve socialization, communication, and friendship. There is also evidence that regular physical education can reduce or prevent mild to moderate depression (Ioan-Sabin et al., 2018). According to Pyper et al. (2016), physical activity can be promoted or inhibited by parental and family behaviors and the environment. There is evidence to suggest that directing parents or families to certain behaviors directly, in contrast to other constructs (e.g., attitudes), may be effective strategies for improving physical activity in children. Pyper et al. (2016) and Barbu et al. (2019) agree that at no other point in history an active lifestyle had played such a dominant role in everyday life. When it comes to physical activity as part of a healthy lifestyle, it is important to single out the importance of physical activity for socialization and education: social events, sports shows, support campaigns, social marketing (Barbu et al., 2019). The authors distinguish that physical health is essential for a balance between mental health and positive thinking, as mental and emotional health can provide a rational approach to health and physical illness (Barbu et al., 2019).

Mental state. In order to prevent mental disorders, it is very important to establish a healthy lifestyle that promotes psychological well-being. Psychological health is affected not only by personality traits, general living conditions, and life events, but also by simple daily behaviors that a person can change. These can be daily activities (reading books, cooking), the environment (work environment, family relations, social life), and taking care of one's well-being (adequate sleep, complete nutrition, physical activity). Evidence suggests that such lifestyle factors have a positive effect on psychological status by reducing depression and anxiety (Velten et al., 2014).

Thus, in summary, a healthy lifestyle consists of several key factors that determine a person's well-being, namely a healthy diet, physical activity, and a psychological state. None of these factors can work in isolation, and their balance creates harmony that we can described as a healthy lifestyle.

\section{Analysis of social marketing impact on consumers}

After discussing the concepts of social marketing and healthy lifestyle, the impact of social marketing on consumers' choice of healthy lifestyle will be discussed below.

Hastings et al. (2011) single out three principles by which social marketing is effective and impactful for the consumer:

1. Brand promise is consistently promoted in different elements of the marketing communication complex (e.g., advertising, public relations, sales promotion, etc.).

2. Supporting how one of the elements of 4P's works purposefully together with the other elements of 4P's product, price, location.

3. The communication focus is not on providing information but on changes in social behavior and actions such as testing and retention.

Liao (2020) conducted a study to determine the criteria for social marketing success to improve health promotion outcomes using a decision-making approach. The researcher involved volunteers from Taiwan's Buddhist charity Dharma, which is physically involved in promoting a healthy lifestyle through a vegetarian diet, organizing events and activities and chronic disease health management campaigns. Respondents who were in leadership positions or playing an important role in health promotion and had at least 15 years of experience in promoting a healthy lifestyle were selected as survey respondents. The results of the study showed that creating an effective communication message is the most important factor for a successful social marketing campaign. According to the author, a social 
marketer should create an engaging message to draw the attention of the target audience to behavioral changes. This shows that effective reporting methods have a significant impact on the intentions of a health promotion strategy. The research data confirmed that the most important factor of social marketing is to create an attractive message that would encourage the target audience to promote a healthy lifestyle (Liao, 2020, p. 14). Social marketing uses systematic marketing techniques that motivate the target audience to change their behavior voluntarily. This strategy aims to encourage the behavior change of the target audience and to facilitate voluntary change and support. Allowing an audience to change behavior voluntarily rather than compulsively is a key goal of social marketing. Liao (2020) identifies appropriate media and audience orientation as equally important criteria. In order to successfully implement a social marketing campaign in the field of health promotion, the needs of consumer must be taken into account and message disseminated to engage the audience (Liao, 2020).

A study of social marketing impact has also been conducted in South America by Lorenzo et al. (2020) on alcohol consumption among young people. According to the authors, Latin American regions have the highest alcohol and tobacco consumption compared to the rest of the world. Therefore, social marketing is one of the most effective tools that can influence consumers to promote a healthier lifestyle. The aim of this study was to evaluate the impact of social marketing on reducing alcohol and tobacco use for students from the Army University ESPE in Ecuador. Summarizing the results of the study, it could be observed that the impact of social marketing on young people due to alcohol consumption was related to the influence of relatives and friends, as well as problems such as illness, economic instability, and inferior family (Lorenzo et al., 2020). Social marketing was also found to be moderately effective in influencing student behavior, and the most effective means of communication were identified as social networks and promotional campaigns on harmful effects as well as various messages related to ethics and values, alcohol and tobacco reduction actions, health and lifestyle messages. The study also found that age has a significant impact on social marketing effectiveness - young people pay more attention to social marketing campaigns, consider and apply the examples to themselves. In addition, research has shown that the effectiveness of social marketing is determined by the community and the values it pursues (Lorenzo et al., 2020).

McKay-Nesbitt and Yoon (2015) also conducted a study that aimed to determine how social marketing messages affect physical activity when a health organization is disclosed as a source of communication. The researchers conducted three studies: two of them used experimentally manipulated messages, and one used real TV advertising. The results of the study showed that social marketing communication messages that show an appropriate pattern of behavior may be more effective than fun content messages when a health organization is revealed as content producer compared to when the advertiser is not disclosed. This suggests that the sponsor of the information disseminated (i.e., the health organization as a brand) may influence consumers' attitudes toward better physical activity (McKay-Nesbitt $\&$ Yoon, 2015). The results of the study suggest that health organizations can maximize the effectiveness of social marketing communication by depicting actual activities rather than entertaining messages. This suggests that the content of a promotional message must be consistent with the position or values of disseminating organization, and when consumers are unaware that the message disseminator is a health organization, entertaining content messages are equally effective in promoting physical activity (McKay-Nesbitt \& Yoon, 2015).

Another study on the impact of social marketing on consumers was conducted in Australia, examining the attitudes of Australian aborigines towards a healthy lifestyle and the factors that shape it. Berends and Halliday (2018) examined the effectiveness of a project for Australian aborigines after governments in Australia advocated the use of social marketing to promote a healthy lifestyle and address rising rates of chronic diseases. The Deadly Sport Gippland project was launched in 2014 on the social network Facebook, with a calendar and recordings of local events as well as information about a healthy lifestyle. The aim of this study was to find out what motivates the target audience to change their lifestyle, and to single out social marketing methods that can change consumer behavior to the desired. The results of the survey showed that the campaign on Facebook was effective - when asked what they thought the campaign was about, the majority (85\%) said "improve nutrition", and to a lesser extent (61\%) "about changes in their food and drink diet", and as many as $39 \%$ of respondents have actually changed their habits based on the influence of the campaign. When asked by respondents what determined the effectiveness of the campaign, the survey data showed that attitudes towards a healthy lifestyle come from family values, as well as opportunities such as financial status and place of residence (Berends \& Halliday, 2018).

Summarizing the research conducted by researchers, it has been observed that social marketing is used to find out its impact on consumers in various areas of healthy lifestyle - physical activity, nutrition, substances use. The analysis of the research found that consumers are influenced and encouraged to promote healthy lifestyle by an effective communication message, as well as the consumers' personality, such as age, social status and the external environment factors - the influence of the community and others on decision-making. Based on the results of the research analysis, a model of the impact of social marketing on consumers' choice of a healthy lifestyle has been developed (see Figure 3). This model consists of three main parts, each of which, in terms of its size and the number of influencing factors, shows the importance and impact of the factor on the consumer's choice of a healthy lifestyle. The influence of the factors of the communication message is the largest, which means that it has the greatest impact on consumers, slightly lower influence is from personality factor, whereas the external environment is the least influential factor. 


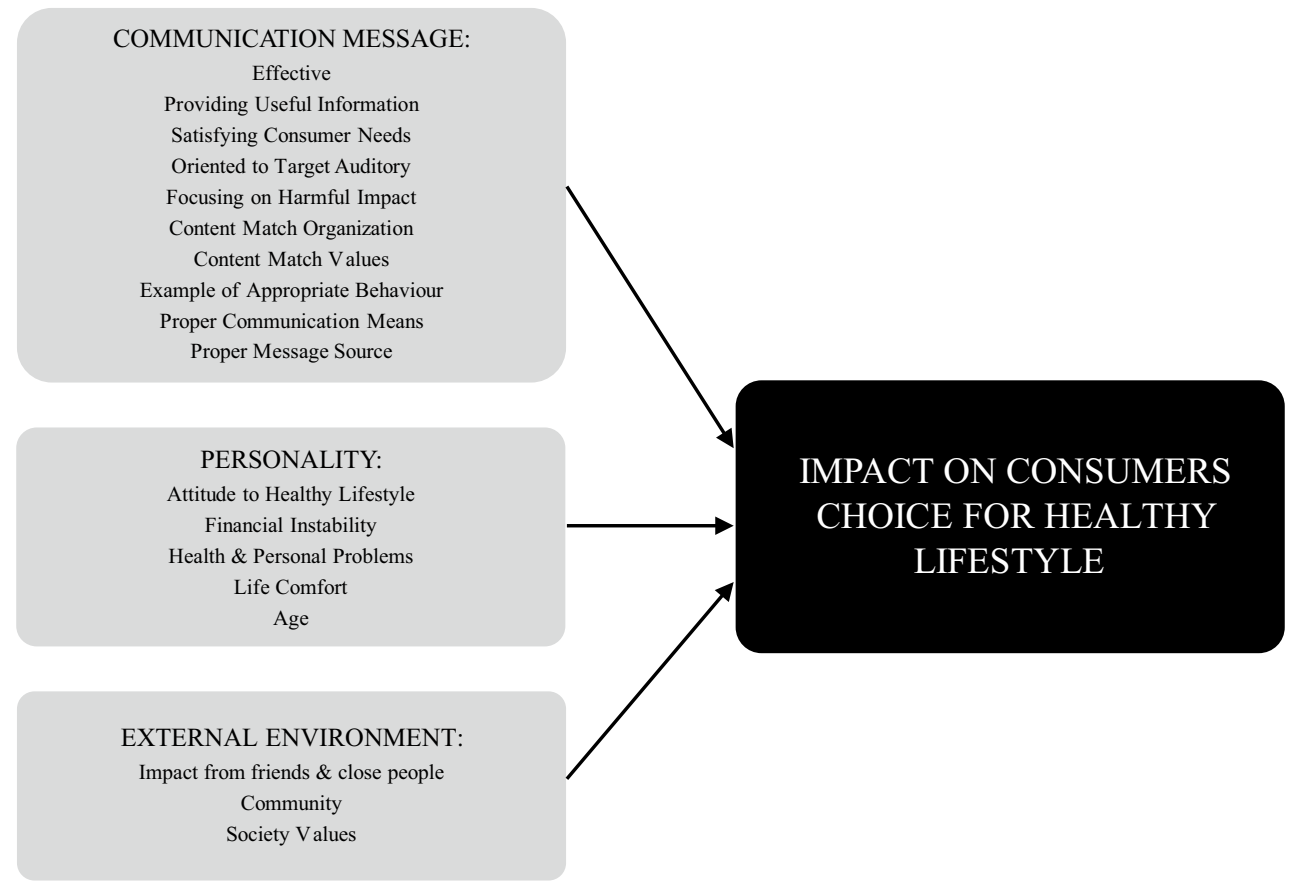

Figure 3. Model for social marketing, personality and external environment impact on consumers healthy lifestyle choice (source: developed by authors)

The above model identifies three main groups of factors that influence consumers' healthy lifestyle choices:

1. Communication message. It is no coincidence that this factor is depicted as the largest - according to research data, the communication message has the greatest impact on the influence of consumers in choosing a healthy lifestyle. In essence, a communication message is a means of reaching and influencing consumers at a particular time, place, and by certain means.

- The content of an effective communication message meets the needs and benefits of the consumer, sets a good example of behavior and motivates consumers to change, adopt a certain attitude, try an activity or give up a harmful habit. For a communication message to be effective, it is necessary to analyze the target audience and find the most appropriate communication solution for the maximum effectiveness.

- Target audience is a critical point in any communication message. In order for a communication message to be effective and reach the desired consumers, it must be targeted to the specific audience for which it is intended. This means that before taking any marketing action, the target audience segment should be determined and analyzed.

- Communication message must provide useful and relevant information to the target audience about a particular problem, its solution or motivation for change.

- Consumers' needs and satisfaction are also an important factor in determining the impact of a communication message. Consumer expects a certain message, in a certain place, not opposite to the values.

- Emphasizing harmful effects enhances the effectiveness of communication message. As for most consumers, demonstrating harmful effects helps to get rid of harmful habits and helps to adopt new approaches to life.

- Also, an example of good behavior affects consumers. Often, companies and organizations choose controversial messages that exemplify both harmful and appropriate behavior, thus emphasizing the importance of their behavior and the consequences of possible actions.

- It is important that the content of communication message would be in line with organizations' position and values, which means that medical institutions should only talk about health-related topics and car manufacturers about cars and vehicles, not the other way around.

- The choice of the right dissemination tool and mean is a particularly important factors while considering the target audience, content of the message and the effect aimed to achieve. According to the various research results, advertising as the mean of social marketing is the most effective.

- The right person for communication and the match between his image and activities with promoted content is very important to affect the consumers.

2. Personality. According to research data, the environment as a factor is very important but still less influential than the communication message when choosing a healthy lifestyle.

- Health and personal issues determine consumer's reaction to social marketing. Consumers reaction to the 
social marketing message depends on his current lifestyle. If he has health or personal problems, he can respond positively to a message that is relevant to him and offers a way for solution.

- Financial instability is an important factor negatively influencing consumer decisions, as any change requires financial investment and commitment.

- The influence of the family on the life of every person is indisputable, so it is obvious that attitudes towards a healthy lifestyle often come from the family. The effectiveness of social marketing will be greater if the person comes from a family promoting a healthy lifestyle.

- What is more, the impact of social marketing on the consumer depends also on the comfort of the consumer's life.

- The age of the consumer also has influence, as children, teens, adults, and seniors will all respond differently to the same message, depending on their age, lifestyle and health status.

3. External environment. This factor, according to research data, also strongly influence consumer attitudes, but less than personality or communication message.

- The influence friends and close people often determine the decisions. Some users have strong opinions and do not allow themselves to be affected, but for others, the opinions of friends and close people are important and often influence decisions.

- Community is also an important external environment factor in determining the impact of social marketing on the consumer. Some communities have strong values and encourage community members to adopt attitudes that are acceptable to them.

- Well-established values in society also encourage consumers to respond positively to the social marketing message. Positive examples seen in society encourage consumers to make positive decisions and replace bad habits with positive ones.

Thus, social marketing is definitely an effective tool to encourage consumers to change their lifestyles to be healthier, but it is important to understand that not only social marketing tools have impact, but also each personality, values and external environment do so.

\section{Conclusions}

The examined approaches in the scientific literature allow to conclude that social marketing is perceived as a change in behavior. Social marketing refers to efforts focused on factors that shape consumer behavior that improve health, help prevent injury, protect and preserve the environment, contribute to communities, and increase financial satisfaction and stability. This means that social marketing can shape consumer behavior and steer it in the desired healthier direction.

External environment factors were identified as influencing consumers' choice for healthy lifestyle, such as the influence of friends and close people, community and its expressed values.

Consumer personality is also an important factor influencing healthy lifestyle choices. It has been determined that personal characteristics such as consumer age, attitudes towards healthy lifestyle, values, financial and family situation play important roles in the process of healthy life-style choice.

The impact of social marketing on consumers' choice of a healthy lifestyle includes message-related factors, like selection of the effective communication message content that meets consumer needs and shows positive behavior examples, also the appropriate media and time for the message dissemination.

\section{Disclosure statement}

Authors declare no competing financial, professional, or personal interests from other parties.

\section{References}

Almestahiri, R., Rundle-Thiele, S., Parkinson, J., \& Arli D. (2017). The use of the major components of social marketing: a systematic review of tobacco cessation program, Social Marketing Quarterly, 23(3), 232-248. https://doi.org/10.1177/1524500417704813

Andreasen, A. R. (1994). Social marketing: its definition and domain. Journal of Public Policy \& Marketing, 13(1), $108-114$. https://doi.org/10.1177/074391569401300109

Azzurra, A., \& Paola, P. (2009, September 3-6). Consumers' behaviours and attitudes toward healthy food products: The case of organic and functional foods. In Paper Prepared for Presentation at the 113th EAAE Seminar "A Resilient European Food Industry Nd Food Chain in a Challenging World". Chania, Crete, Greece.

Barbu, M. C. R., Burcea, G. B., Dumitru, R., \& Popescu, M. C. (2019). The contribution of sport to a healthy life. Studia Universitatis Babeş-Bolyai Educatio Artis Gymnasticae, 64(4), 31-42. https://doi.org/10.24193/subbeag.64(4).28

Berends, L., \& Halliday, R. (2018). Capacity building and social marketing promotes healthy lifestyle behaviour in an Australian aboriginal community. Australian Journal of Rural Health, 26(4), 279-283. https://doi.org/10.1111/ajr.12421

De, L. C., \& De, T. (2019). Healthy food for healthy life. Journal of Global Biosciences, 8(9), 6453-6468. 
Eurobarometer. (2017). Public health. https://ec.europa.eu/health/eurobarometers_en

Firestone, R., Rowe, C. J., Modi, S. N., \& Sievers, D. (2017). The effectiveness of social marketing in global health: A systematic review. Health Policy and Planning, 32(1), 110-124. https://doi.org/10.1093/heapol/czw088

French, J., \& Gordon, R. (2019). Strategic social marketing - for behaviour and social change (pp. 1-16). Sage Publication.

Goldberg, M. E., Fishbein, M., \& Middlestadt, S. E. (Eds.). (2018). Social marketing: Theoretical and practical perspectives (pp. 2-14). Psychology Press. https://doi.org/10.4324/9781315805795

Gordon, R., Russell-Bennett, R., \& Lefebvre, R. C. (2016). Social marketing: the state of play and brokering the way forward. Journal of Marketing Management, 32(11-12), 1059-1082. https://doi.org/10.1080/0267257X.2016.1199156

Hastings, G., Angus, K., \& Bryant, C. (Eds.). (2011). The Sage handbook of social marketing (pp. 44-61). Sage.

Ioan-Sabin, S., \& Pomohaci, M. (2018). Developing a healthy lifestyle of students through the practice of sport activities. Land Forces Academy Review, 23(3), 207-218. https://doi.org/10.2478/raft-2018-0025

Kotler, P., \& Zaltman, G. (1971). Social marketing: an approach to planned social change. Journal of Marketing, 35(3), 3-12. https://doi.org/10.1177/002224297103500302

Kottke, T., Wilkinson, J., Baechler, C., Danner, C., Erickson, K., O’Connor, P., Sanford, M., \& Straub, R. S. (2016). Health care guideline healthy lifestyles how. Grade. http://www.gradeworkinggroup.org/

Lee, N. R., \& Kotler, P. (2015). Social marketing - changing behaviors for good (5 $5^{\text {th }}$ ed.) (pp. 2-41). Sage Publications.

Liao, C. H. (2020). Evaluating the social marketing success criteria in health promotion: A f-dematel approach. International Journal of Environmental Research and Public Health, 17(17), 1-19. https://doi.org/10.3390/ijerph17176317

Lorenzo, A. F., Andrés, A., Villamarín, B., Michelle, D., \& Cadena, P. (2020). Influencia del marketing social en el consumo de alcohol y tabaco en los estudiantes universitarios [The influence of social marketing in alcohol and tobacco consumption in university students]. Cuban Journal of Higher Medical Education, 34(1), 1-14.

McGovern, C. M., Militello, L. K., Arcoleo, K. J., \& Melnyk, B. M. (2018). Factors Associated with healthy lifestyle behaviors among adolescents. Journal of Pediatric Health Care, 32(5), 473-480. https://doi.org/10.1016/j.pedhc.2018.04.002

McKay-Nesbitt, J., \& Yoon, S. (2015). Social marketing communication messages: How congruence between source and content influences physical activity attitudes. Journal of Social Marketing, 5(1), 40-55. https://doi.org/10.1108/JSOCM-04-2013-0021

Pyper, E., Harrington, D., \& Manson, H. (2016). The impact of different types of parental support behaviours on child physical activity, healthy eating, and screen time: A cross-sectional study. BMC Public Health, 16(1), 568. https://doi.org/10.1186/s12889-016-3245-0

Rauf bin Ridzuan, A., Abu Karim, R., Hanisah Marmaya, N., Abdul Razak, N., Khairin Nawwarah Khalid, N., \& Nizam Muhamad Yusof, K. (2018). Public Awareness towards healthy lifestyle. International Journal of Academic Research in Business and Social Sciences, 8(10), 927-936. https://doi.org/10.6007/IJARBSS/v8-i10/4790

Robards, F. (2014). Healthy lifestyle. Youth health resource kit. In NSW Kids and Families, Chapter: 3.12 (pp. 189-193). NSW Government.

Serrat, O. (2017). The future of social marketing knowledge solutions. Springer Singapore. https://doi.org/10.1007/978-981-10-0983-9_17

Shawn, M. (2015). Social good and the competitive advantage of doing it well. In Finance Undergraduate Honors Theses. https://scholarworks.uark.edu/finnuht/22

Slade, M., Oades, L., \& Jarden, A. (2017). Wellbeing, recovery and mental health (pp. 311-324). Cambride University Press. https://doi.org/10.1017/9781316339275

Velten, J., Lavallee, K. L., Scholten, S., Meyer, A. H., Zhang, X. C., Schneider, S., \& Margraf, J. (2014). Lifestyle choices and mental health: A representative population survey. BMC Psychology, 2(1). https://doi.org/10.1186/s40359-014-0055-y

World Health Organization. Regional Office for Europe. (1999). Healthy living: what is a healthy lifestyle (19 p.)? WHO Regional Office for Europe. https://apps.who.int/iris/handle/10665/108180 